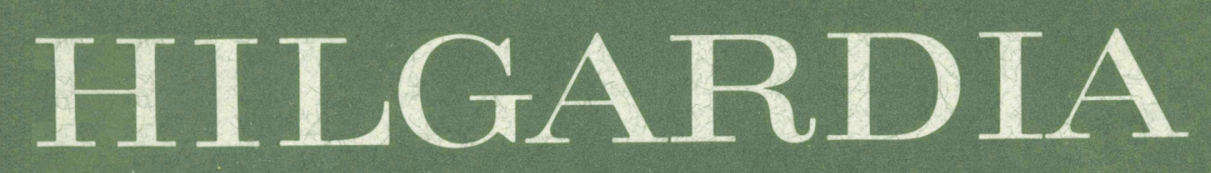

A JOURNAL OF AGRICULTURAL SCIENCE PUBLISHED BY THE CALIFORNIA AGR ICULTURALEXPERIMENTSTATION

Volume 47, Number $1 \cdot$ February, 1979

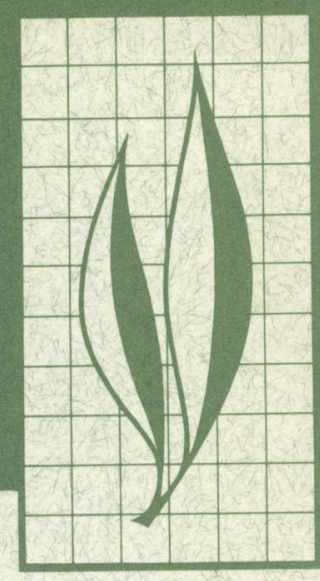

\title{
Biological Control of the
}

Walnut Aphid in California: Impact of the Parasite, Trioxys pallidus

R. van Den Bosch, R. Hom, P. Matteson, B. D. Frazer

P. S. Messenger, and C. S. Davis 


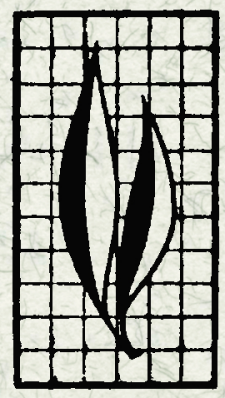

The interrelationship of an Iranian ecotype of Trioxys pallidus (Hal.) (Hymenoptera: Aphidiidae) and the walnut aphid, Cbromapbis juglandicola (Kalt.), (Homoptera: Callaphididae), was assessed over a 4-year period at two localities in California. Limited additional data were obtained from other localities. Trioxys pallidus, a highly efficient parasite, which is biologically adapted to and phenologically synchronized with $C$. juglandicola, has brought about substantial biological control of this pest. Trioxys pallidus substantially dampens the aphid's vernal oscillation, and normally restrains the amplitude of the summer and autumnal oscillations. Major economic benefits have been realized by the elimination of the aphid as a pest in springtime. Trioxys pallidus is at times heavily attacked by non-specific hyperparasites, but these, at most, hinder it but slightly. Certain insecticides can disrupt $\boldsymbol{T}$. pallidus activity, permitting aphid outbreaks. Prolonged aphid scarcity, possibly abetted by hyperparasitism, also may cause a breakdown in parasite activity and a temporary aphid resurgence in midseason. During the 4 years of investigation, this occurred on one occasion in one of the study plots. More than one-half million dollars have accrued annually to the California walnut industry as a result of the $C$. juglandicole biological control program.

\section{THE AUTHORS:}

R. van den Bosch (deceased) was Professor, Division of Biological Control, Department of Entomological Sciences, Berkeley.

R. Hom is Staff Research Associate, Division of Biological Control, Department of Entomological Sciences, Berkeley.

P. Matteson, formerly Research Assistant, Division of Biological Control, Berkeley, is with International Institute of Tropical Agriculture, Ibadan, Nigeria.

B. D. Frazer, formerly Research Assistant, Division of Biological Control, Berkeley, is with Agriculture Canada, Research Station, Vancouver, B.C., Canada.

P. S. Messenger (deceased) was Professor, Division of Biological Control, Department of Entomological Sciences, Berkeley.

C. S. Davis is Extension Entomologist, Cooperative Extension, University of California, Berkeley. 


\section{Biological Control of the Walnut Aphid in California: Impact of the Parasite, Trioxys pallidus ${ }^{1}$}

\section{INTRODUCTION}

Two ECotypes of the parasite Trioxys pallidus (Hal.) have been introduced into California for control of the walnut aphid, Chromaphis juglandicola (Kalt.). The first, obtained from France in 1959, was colonized widely in the State for several years. However, it was apparently ill-adapted to the hot, arid climate of the major walnut-producing areas of the Central Valley; it gained a foothold only along the south coastal plain (van den Bosch et al., 1962; van den Bosch, Schlinger, and Hagen, 1970).

The second ecotype was obtained from Iran in 1968 in the expectation that it would be better adapted to the California interior. This hope was quickly borne out when the Iranian ecotype became established at several places during the summer and autumn of the year of introduction. The parasite spread explosively over California in the ensuing two years, and by 1970 it had essentially colonized all major walnut-growing areas of the state (van den Bosch et al., 1970).

Frazer and van den Bosch (1973) described the interrelationship of the parasite and host in a small, non-commerical grove of walnut trees (Juglans regia $\mathrm{L}$.) in the Reliez Valley, 18 miles east of San Francisco. While study provided insight into the efficacy of $T$. pallidus as a biological control agent, it was not designed to measure the parasite's overall impact on the walnut aphid throughout California. Such studies were made subsequently at scattered localities in central California, and these form the basis of the current paper.

\section{MATERIALS AND METHODS}

The spread of the Iranian ecotype of $T$. pallidus was so rapid that the 1969-1970 Reliez Valley study was the only one that permitted an assessment of the population dynamics of the host, C. juglandicola, before and after the establishment of the new Iranian parasite.

The studies reported here were made in areas where host-parasite equilibrium presumably had been reached. Major efforts were made at two places: in the grove in Reliez Valley used by Frazer and van den Bosch (1973), and in a commercial grove near Hanford, 190 miles south-east of San Francisco in a major walnut-growing area of the San Joaquin Valley. These studies were

\footnotetext{
'This manuscript was accepted for publication May 31, 1978.
} 
conducted over four seasons, 1971 through 1974. Two less intensive studies, in the San Joaquin and Sacramento valleys, provided supporting data.

\section{Reliez Valley study}

In the Reliez Valley study the sampling regime was simplified from that of Frazer and van den Bosch (1973). Each year four trees of the Concord variety were sampled from early spring until late autumn. Sampling intervals varied, ranging from about 1 to 3 weeks.

On each sampling date, living and mummified aphids were counted on 50 compound leaves randomly selected from the skirts of the four trees. Data on live aphid population trends only are presented in this paper.

Aphid predators were not recorded. Frazer and van den Bosch (1973) reported a scarcity of predators after $T$. pallidus invaded their study plot. In the current study, we felt that useful information on predation could not be obtained without the expenditure of an excessive amount of time and effort. During the four seasons of the study, significant numbers of predators were rarely seen in either the Reliez Valley or Hanford groves.

The degree of parasitization in the plots on each sampling date was determined by dissection samples of 4 thinstar aphids. At least 50 aphids were dissected each time except on those occasions when aphids were so scarce that it was impractical to obtain the desired 50 dissectable specimens.

Hyperparasitism was assessed by holding field-collected aphid mummies individually in small gelatin capsules and recording the emergent primary parasites and their hyperparasites.

\section{Hanford study}

The Hanford study was conducted in a 20-acre commercial grove of the Hartley variety. The sampling tech- nique was similar to that employed in Reliez Valley, except that the 50 compound leaves examined on each sampling date were taken, one per tree, from trees scattered throughout the grove. Primary parasitism and hyperparasitism were studied in the same way as in the Reliez Valley.

\section{Pesticide treatments}

During August, 1971, the Reliez Valley plot was treated with phosphamidon to control walnut huskfly, Rhagoletis completa Cress. This treatment adversely affected both the walnut aphid and T. pallidus, and neither were numerous during the remainder of the year. The plot was not treated with a pesticide in subsequent years.

During the winter of 1970-71, the Hanford plot was treated with a dormant spray of diazinon and oil to control scale insects, and in July, 1971, it was treated with Omite ${ }^{\circledR}$ to control spider mites. No other pesticides were applied to the grove during the course of the study.

The effects of insecticides on populations of the walnut aphid and the percentages of parasitization were assessed by a test in a commercial orchard in 1972, at Tracy, 55 miles east of San Francisco. The data from two of the treatments and the untreated control are summarized in Table 1. About 104 gallons of spray were used per tree.

\section{The walnut aphid economic threshold}

The economic threshold for the walnut aphid is considered to be 10 to 20 aphids per leaflet [10 to 20 aphids, Pest and Disease Control Program for Walnuts, University of California (1973), 15 to 20 aphids, Michelbacher and Ortega (1958)] for early heavy-bearing varieties. In commercial practice, infestation levels are determined by averaging the number of aphids counted on a sampling of leaflets taken from trees 


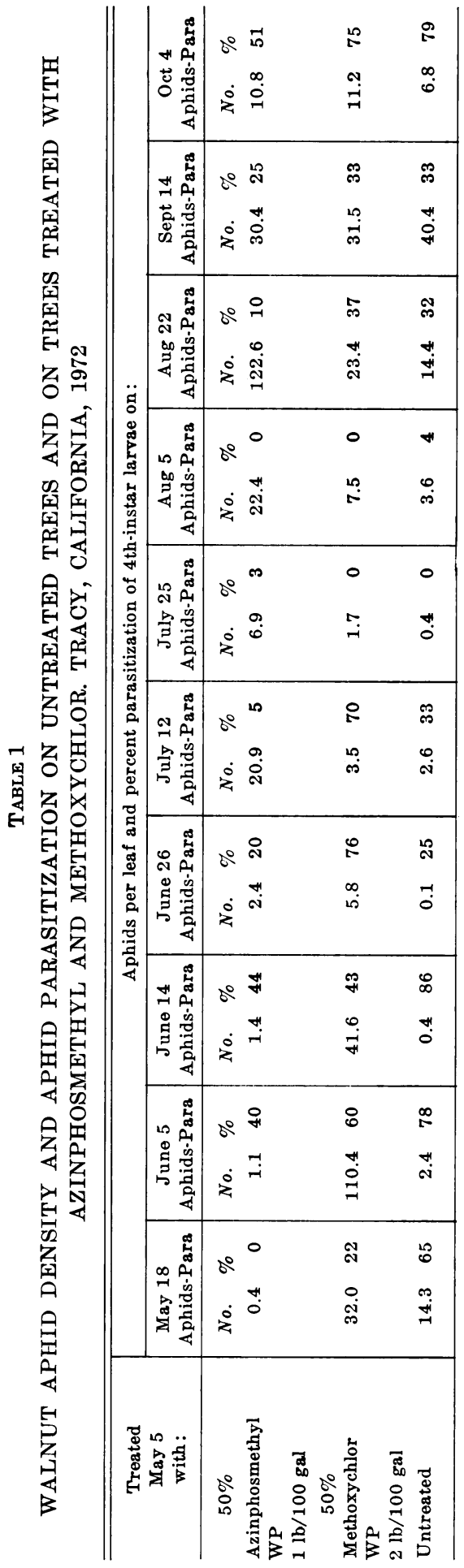

scattered throughout a grove. The leaflet examined on given compound leaves (normally composed of seven leaflets) is one or the other of the pair located next to the terminal leaflet.

Chromaphis juglandicola is potentially most harmful during its springtime oscillation, which normally peaks in May. Sibbett, Barnes, and Davis (1970), in a paper developed from data obtained before the widespread establishment of $T$. pallidus, stated: "It is noteworthy that the period of intense walnut aphid infestation coincides with the period of most rapid growth of walnut size. Hence walnut aphid (sic) interferes with highest demand on leaf performance." In a subsequent paper, these authors (Sibbett et al., 1971) again noted the crucial nature of "economic" walnut aphid populations during the period of rapid increase in nut size. It was emphasized in both of the studies just cited, that the peak of the "intense walnut aphid infestation" and "economic" population occurred in May. In 1969 this peak was 602 aphids per leaf, and in 1970 it was 378 .

As far as we are aware, these two studies are the only ones dealing directly with the economic impact of $C$. juglandicola, and these only concern springtime populations of the aphid. There does not appear to be a clearly, or even vaguely defined, economic threshold for $C$. juglandicola in mid or late season. However, if studies were to be conducted, the economic thresholds established for the more advanced stages of the season almost certainly would be substantially higher than the one now used for early season infestations, since in mid and late season the leaves are no longer under heavy demand to provide nutrients for rapid nut growth. Our consideration of the economic impact of $T$. pallidus on the $C$. juglandicola problem, unfortunately, can only be with the vernal populations of the aphid. 

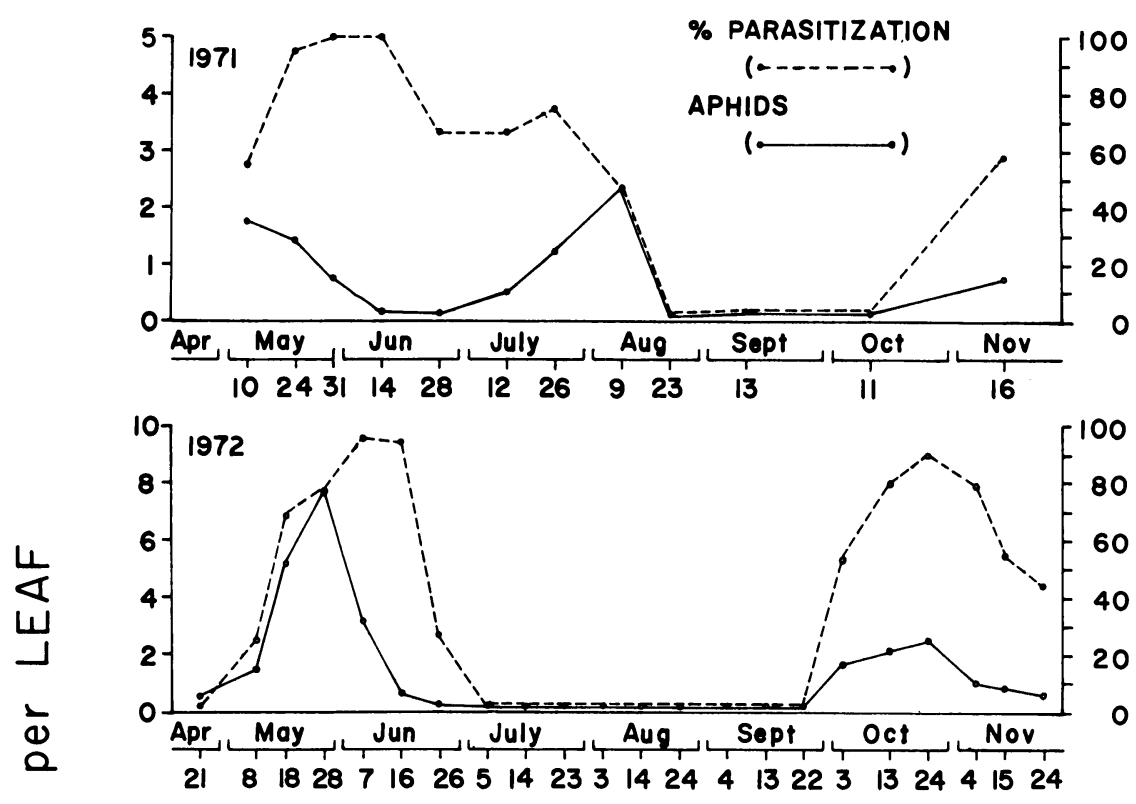

足
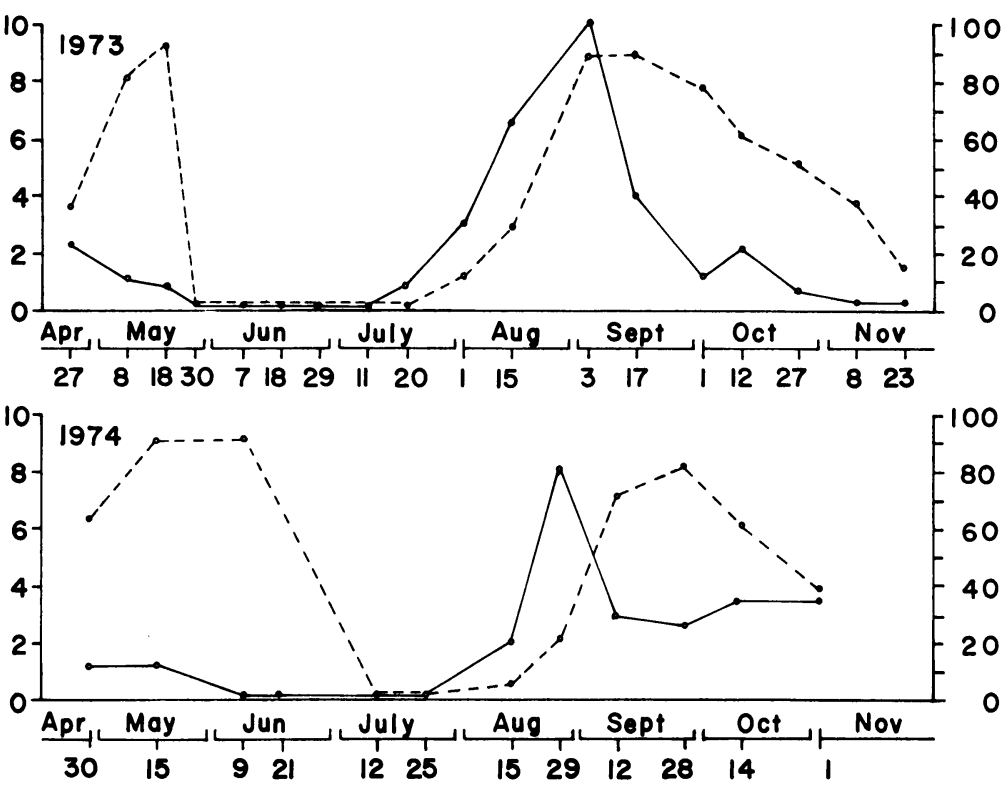

Fig. 1. Population trends of the walnut aphid Chromaphis juglandicola, and parasitization of it by Trioxys pallidus in a small noncommercial walnut grove (Concord variety) in Reliez Valley, Contra Costa County, California, 1971 to 1974. The precipitous drop in aphid abundance and parasitization in August, 1971, followed application of phosphamidon to the grove for huskfly control. 

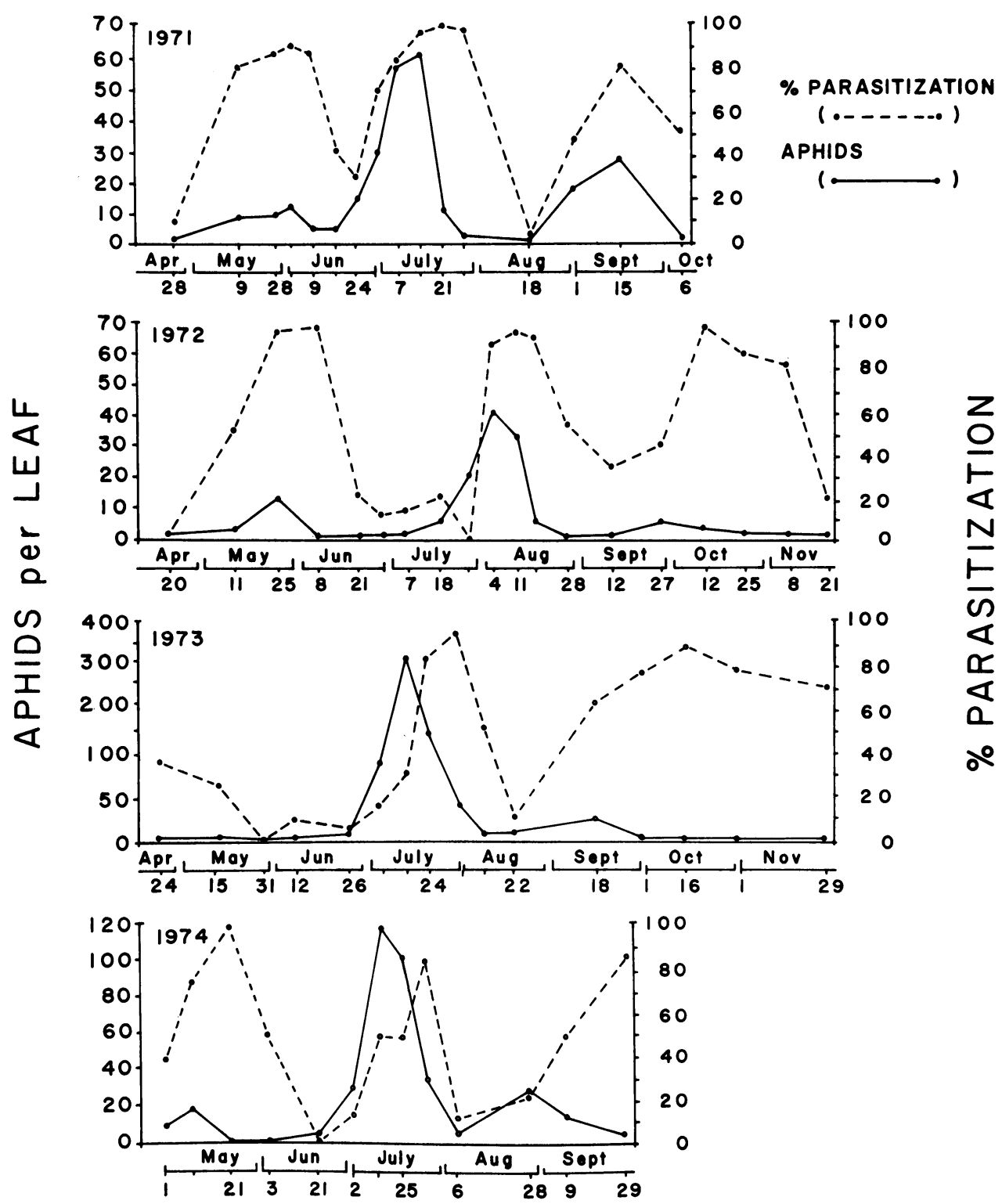

Fig. 2. Population trends of the walnut aphid Chromaphis juglandicola and parasitization of it by Trioxys pallidus in a twenty-acre commercial walnut grove (Hartley variety) located near Hanford, Kings County, California, 1971 to 1974.

In our aphid sampling we counted all individuals on the specified numbers of compound leaves sampled. When desired, the total was divided by the numbers of leaves sampled to get a perleaf average. To convert these averages (e.g., as from Figs. 1 and 2) to a perleaflet value, for ready comparison to the economic threshold, the number per leaf is divided by 7 , the number of leaflets per leaf. 


\section{RESULTS}

\section{Reliez Valley}

The data summarized in Figure 1 reflect the severe impact of T. pallidus on C. juglandicola in the Reliez Valley plot. Each year the aphid population was devastated during springtime and never approached the economic threshold level of 70 to 140 aphids per leaf (10 to 20 or 15 to 20 per leaflet). In 1971 (Fig. 1), the aphid population showed signs of increase in late July and early August after an 8-week period of very low density; however, the grove was treated with the insecticide phosphamidon for huskfly control, and the aphid population was reduced to an extremely low level. Thereafter, both the aphid and parasite populations remained at low levels for two months before showing some increase in late autumn. At the time we speculated that the overwintering population of $T$. pallidus may have been so low that the parasite would have little impact in the spring of 1972, and an aphid population explosion might result. But the 1972 data (Fig. 1) show that although the aphid attained a higher springtime density than it had the previous year, the numbers hardly aproached an injurious level before they were reduced by the parasite. Thereafter, aphid numbers remained at a low level from midJune through the end of August, when they again began to increase. The parasite then quickly responded and took a heavy toll.

The events of 1973 and 1974 resembled those of the two previous years in that heavy parasitization kept the aphid at very low levels at all times. The low vernal peaks of 1973 and 1974 were followed by low peaks only in late summer, so that there were two oscillations each year (as was the case in 1972). Frazer and van den Bosch (1973) attributed a mid-summer aphid eruption in $\mathbf{1 9 7 0}$ to the activity of the Argentine ant,
Iridomyrmex humilis Mayr, which interfered with $T$. pallidus. The ant population was not monitored during the current study and we do not know whether the absence of ants may have been a factor in the mid-summer scarcity of aphids. However, conspicuous ant activity was not observed on the trees at any time.

\section{Hanford}

The Iranian ecotype of $T$. pallidus was first released at the Hanford study site in the autumn of 1968 , and it became established at that time. The parasite was also released and established at other places in the Hanford area in 1968 and 1969. Thus, by April, $1971, T$. pallidus occurred in all the walnut-growing areas surrounding the study plot and presumably had reached equilibrium with its host.

The data from the four-year study are summarized in Figure 2. They depict 12 host-parasite oscillations during the four years, and show the remarkable control that $T$. pallidus exerted over the springtime populations of the walnut aphid during that period.

The four-year host-parasite relationship depicted in Figure 2 represents perhaps as many as 40 aphid and parasite generations. It is an unusual record of reciprocal density-dependence from the field. The large number of hostparasite generations and the relative stability of the walnut environment unquestionably contributed to the remarkable clarity of the host-parasite relationship.

At Hanford as in the Reliez Valley in typical years (i.e., 1971, 1972, 1974) $T$. pallidus heavily parasitized $C$. juglandicola during springtime, severely dampening the aphid's vernal oscillation. But at Hanford, unlike Reliez Valley, as parasite pressure relaxed in late spring and early summer, there was a 
TABLE 2

WALNUT APHID DENSITY AND PARASITIZATION ON UNTREATED TREES IN COMMERCIAL ORCHARISS AT TWO CALIFORNIA LOCATIONS (1972)

\begin{tabular}{|c|c|c|c|c|c|}
\hline \multicolumn{3}{|c|}{$\begin{array}{c}\text { Butte City } \\
\text { (Walnut Growers Inc.) }\end{array}$} & \multicolumn{3}{|c|}{$\begin{array}{c}\text { Tracy } \\
\text { (Hugh Crawford Ranch) }\end{array}$} \\
\hline \multirow[t]{2}{*}{ Date } & Aphids/leaf & Parasitization * & Date & Aphids/leaf & Parasitization* \\
\hline & number & percent & & number & percent \\
\hline May 17 & 0.5 & $\dagger$ & May 18 & 14.2 & 65 \\
\hline June 6 & 2.7 & 66 & June 5 & 2.3 & 78 \\
\hline June 20 & 3.6 & 82 & June 14 & 0.3 & 86 \\
\hline July 5 & 3.8 & 67 & June 26 & 0.1 & 25 \\
\hline July 26 & 4.4 & 14 & July 12 & 1.7 & 33 \\
\hline Aug. 10 & 44.5 & 59 & July 25 & 0.3 & 0 \\
\hline \multirow[t]{4}{*}{ Aug. 31} & 6.3 & 100 & Aug. 5 & 3.5 & 4 \\
\hline & & & Aug. 22 & 14.3 & 32 \\
\hline & & & Sept. 14 & 4.0 & 40 \\
\hline & & & Oct. 4 & 6.8 & 79 \\
\hline
\end{tabular}

* Based on dissection of 4 th instar nymphs.

t No dissectable aphids collected.

summer resurgence of the aphid population which was again depressed by the parasite. Finally, there was a third surge of the aphid population in late summer-early autumn and again a vigorous response by $T$. pallidus.

In 1973 there was a deviation from this pattern. The springtime aphid population remained at an extremely low level without a noticeable peak. The reason for this is not known, but it may have resulted from high mortality of aphid eggs during the severely cold winter of 1972-73. As a consequence of the scarcity of aphids, $T$. pallidus also was rare in the spring of 1973 , and there was a low parasitization peak of only 36 percent. In June the aphid population began to increase, outstripped the extremely rare $T$. pallidus, and quickly reached the highest level of the study (approximately 320/leaf). It is not known whether this population was economically damaging, for it occurred when the foliage was mature and welldeveloped nuts were on the trees. The important implication in the 1973 summer outbreak of $C$. juglandicola is that under circumstances of parasite scarcity the aphid can attain high levels of abundance in mid-summer. The possible economic significance of such elevated mid-season populations can be determined only by careful research.

\section{Butte City and Tracy}

The data on aphid population trends and degree of parasitization obtained in these studies are summarized in Table 2. These limited data are useful in showing the vigorous activity of $T$. pallidus in walnut groves well separated from the main study plots.

The data from both Butte City and Tracy demonstrate the intensive early season activity of $T$. pallidus, its decreased activity in mid-summer, and its response to host resurgence in late summer and early autumn. The maximum aphid infestation levels recorded at these localities were well below the accepted economic threshold.

\section{Hyperparasitism}

Frazer and van den Bosch (1973) reared the hyperparasites Aphidencyrtus aphidivorus (Mayr), Asaphes lucens (Provancher), Asaphes californica Girault, Pachyneuron sp. and Dendrocerus (=Lygocerus) sp. from mummies of $T$. pallidus during the two-year study in Reliez Valley. Aphidencyrtus aphidivorus was overwhelmingly dominant, accounting for more than 98 percent of all the reared hyperparasites. The rearings of the present study yielded a sixth hyperparasite species, Alloxysta sp. A total of 3,105 parasites were reared from 
TABLE 3

NUMBERS OF TRIOXYS PALLIDUS AND ITS HYPERPARASITES REARED FROM MUMMIFIED CHROMAPHIS JUGLANDICOLA* COLLECTED FROM WALNUT AT FOUR CALIFORNIA LOCALITIES (1971 to 1974)

\begin{tabular}{|c|c|c|c|c|c|c|}
\hline \multirow{2}{*}{ Locality/Year } & \multirow{2}{*}{$\begin{array}{l}\text { Number of } \\
T . \text { pallidus } \\
\text { (parasite) }\end{array}$} & \multicolumn{5}{|c|}{ Hyperparasites from $T$. pallidus: } \\
\hline & & $\begin{array}{c}\text { Alloxysta } \\
\text { sp. }\end{array}$ & $\begin{array}{c}\text { Aphidencyrtus } \\
\text { aphidivorus }\end{array}$ & $\begin{array}{c}\text { Asaphes } \\
\text { sp. } \dagger\end{array}$ & $\begin{array}{c}\text { Pachyneuron } \\
\text { sp. }\end{array}$ & $\begin{array}{c}\text { Dendrocerus } \\
\text { sp. }\end{array}$ \\
\hline \multicolumn{2}{|l|}{$\begin{array}{l}\text { Reliez Valley, } \\
\text { Contra Costa Co. }\end{array}$} & \multicolumn{5}{|c|}{ Number } \\
\hline & 32 & 14 & 42 & 2 & 10 & 0 \\
\hline 1972 & 57 & 4 & 17 & 6 & 3 & 0 \\
\hline 1973 & 61 & 4 & 28 & $\mathbf{3}$ & 4 & 2 \\
\hline 1974 & 72 & 1 & 25 & 1 & 1 & 0 \\
\hline Totals & 222 & 23 & 112 & 12 & 18 & 2 \\
\hline \multicolumn{7}{|l|}{$\begin{array}{l}\text { Hanford, } \\
\text { Kings Co. }\end{array}$} \\
\hline 1971 & 318 & 75 & 93 & 168 & 218 & 0 \\
\hline 1972 & 256 & 1 & 42 & 17 & 67 & 0 \\
\hline 1973 & 218 & 0 & 120 & 3 & 5 & 0 \\
\hline 1974 & 144 & 8 & 96 & 4 & 9 & 4 \\
\hline Totals & 936 & 84 & 351 & 192 & 299 & 4 \\
\hline \multicolumn{7}{|l|}{$\begin{array}{l}\text { Tracy, San } \\
\text { Joaquin Co. }\end{array}$} \\
\hline $\begin{array}{l}\text { Butte City, } \\
\text { Butte Co. }\end{array}$ & 69 & 3 & 63 & 3 & 19 & 1 \\
\hline \multirow{2}{*}{$\begin{array}{l}\text { Grand } \\
\text { Totals }\end{array}$} & \multirow{2}{*}{$\begin{array}{l}1518 \\
48.9 \%\end{array}$} & 122 & 673 & 217 & 568 & 7 \\
\hline & & & & $\begin{array}{r}1587 \\
51.1 \%\end{array}$ & & \\
\hline
\end{tabular}

* Numbers of $C$. juglandicola mummies from which these parasites emerged are not tabulated, because many produced nothing (largely due to mortality caused by predators); and these mummies occurred in increasing numbers as each season advanced.

$\dagger$ Species collected: lucens and californica.

mummies collected at all the study sites during the four years of investigation (Table 3 ). Of these, 1,587 or 51.1 percent were hyperparasites, including species in the genera Aphidencyrtus (673, 42 percent) and Pachyneuron (568, 35.7 percent), Asaphes (217, 13.7 percent), Alloxysta (122, 7.7 percent) and Dendrocerus ( $7,0.5$ percent). The relative importance of the hyperparasite species varied with location and year. For example, Pachyneuron dominated at Hanford during 1971 and 1972 but was surpressed by Aphidencyrtus in 1973 and 1974. Aphidencyrtus was the dominant hyperparasite at Reliez Valley in the four years of this study as well as in 1969 and 1970 (Frazer and van den Bosch, 1973).

Despite their abundance and recurrent impact, the hyperparasites did not appear to impair the efficacy of $T$. pallidus. Indeed, during the crucial vernal oscillations at both Reliez Valley and Hanford, T. pallidus each year (Hanford 1973 excepted, as noted above) heavily parasitized the aphid despite having suffered substantial hyperparasitization the previous autumn. Figure 3 shows that in 1971 and 1972 at Hanford, heavy attack by the hyperparasites on $T$. pallidus in springtime occurred after the primary parasite had had its maximum effect on the aphid. It 


\section{(•- - - $) \%$ PRIMARY PARASITISM \\ (E- - - - $)$ \% HYPERPARASITISM \\ $(\bullet)$ APHIDS}

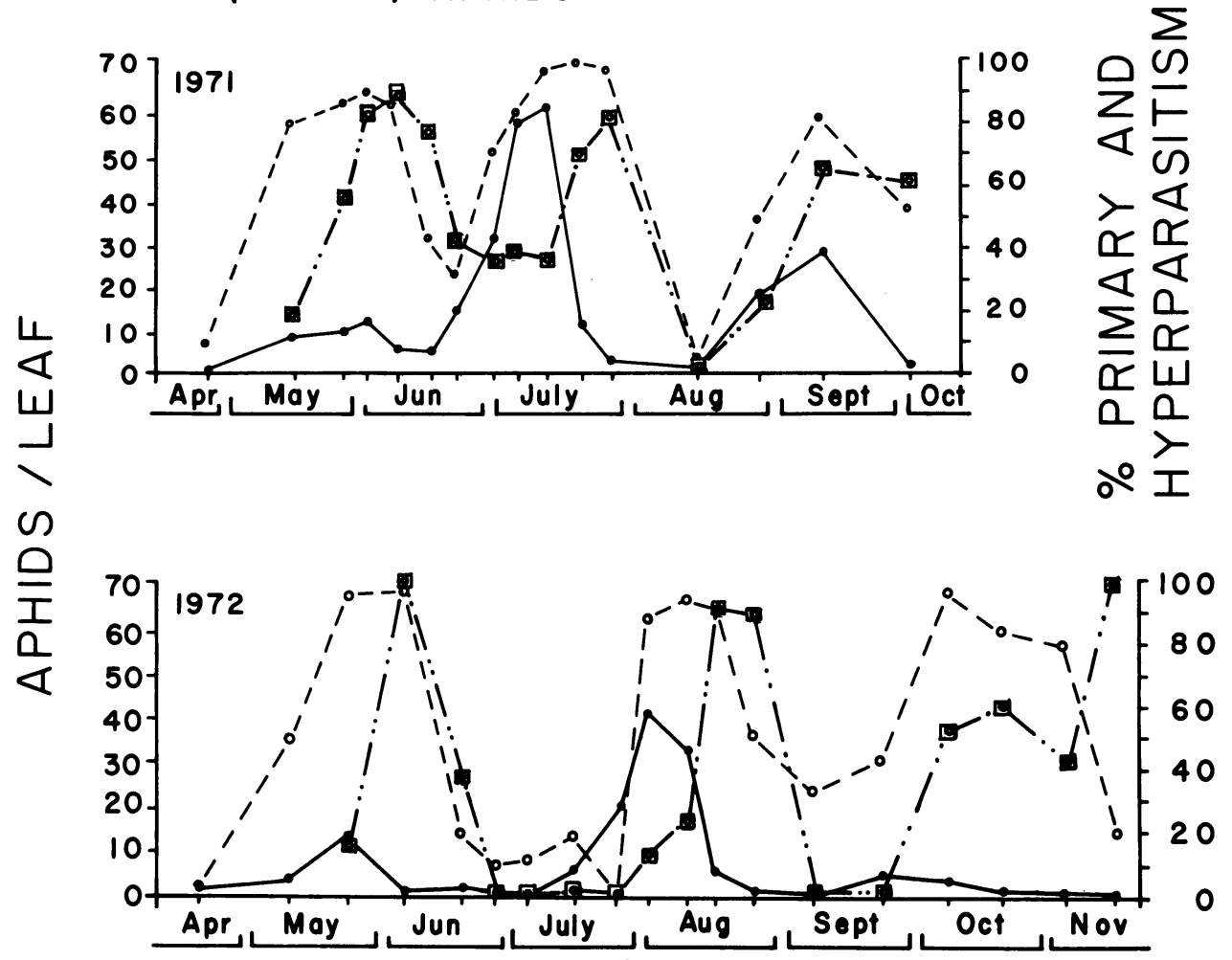

Fig. 3. Population trends of the walnut aphid Chromaphis juglandicola and trends in primary and hyperparasitization of these populations, Hanford, California, 1971 and 1972.

is quite probable that the hyperparasites accelerate the decline of the T. pallidus populations, and depress parasite numbers between spring and mid-summer aphid oscillations. This could be a factor in the release of the $C$. juglandicola populations from parasite pressure, permitting their strong mid-summer upsurge in places such as Hanford.

The major hyperparasites of $T$. pallidus in California were nonspecific. In the walnut orchard environment, $T$. pallidus was a key resource to which the hyperparasites responded in a clearly density-dependent way (Figure $3)$. Such nonspecific hyperparasites are not phenologically keyed to the T. pallidus population, and each year they must "re-discover" the parasite before they can begin to exploit it. This apparently was the reason for the hyperparasite lag which, especially in springtime, permitted $T$. pallidus to effectively reduce the $C$. juglandicola population before it ( $T$. pallidus) was, in turn, exploited by the hyperparasites. 
TABLE 4

CROP LOSSES AND CONTROL COSTS* DUE TO WALNUT APHID IN CALIFORNIA BEFORE AND AFTER INTRODUCTION OF TRIOXYS PALLIDUS (1965 to 1976)

\begin{tabular}{|c|c|c|}
\hline Year & Costs & Notes and events \\
\hline 1965 & $\$ 1,100,000$ & $\longrightarrow$ \\
\hline 1966 & 737,000 & $\longrightarrow$ \\
\hline 1967 & $1,000,000$ & $\longrightarrow$ \\
\hline 1968 & 422,000 & 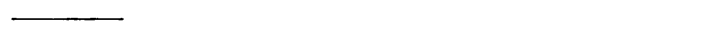 \\
\hline 1969 & 683,000 & Parasite colonization \\
\hline 1970 & 328,000 . & Parasite colonization and first year of impact \\
\hline 1971 & - & \\
\hline 1972 & 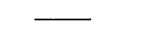 & No reports \\
\hline 1973 & - & \\
\hline 1974 & 29,000 & $\begin{array}{l}\text { Relative costs somewhat higher than for } 1960 \text { s due to increased } \\
\text { insecticide prices and unit value of crop }\end{array}$ \\
\hline 1975 & 138,000 & See 1974 notes; add possible costs of dusty-veined walnut aphid \\
\hline 1976 & 120,000 & See 1975 notes \\
\hline
\end{tabular}

* SOURCE: State of California Department of Food and Agriculture E-82 series, prepared by R. M. Hawthorne and S. Hawkins.

\section{ECONOMIC CONSEQUENCES AND CONCLUSIONS}

In those walnut groves where the studies were conducted, T. pallidus was very effective, and $C$. juglandicola never attained injurious levels during the crucial springtime oscillation. Additional reports from growers, agricultural extension personnel, packing company fieldmen, research entomologists, and California Department of Food and Agriculture entomologists, confirm that there has been a drastic reduction in the walnut aphid problem throughout California following the introduction of the Iranian ecotype of T. pallidus. These reports, coupled with the impact studies reported here, indicate that this parasite has effected a substantial level of commercial control of $C$. juglandicola, essentially eliminating the aphid as a pest during springtime.

Table 4 shows that the reduction of $C$. juglandicola by $T$. pallidus has benefitted the walnut industry by $\$ 0.5$ to $\$ 1$ million annually. This measure of economic benefit is probably conservative, because it does not account for the recent heavy inflation in insecticide costs, nor the increase in the value of the crop.

The walnut aphid biological control program has other interesting aspects.
As C. juglandicola has declined, Callaphis juglandis (Goeże), the dusky veined walnut aphid, has emerged as an apparent "secondary" outbreak pest. Like Chromaphis juglandicola, Callaphis juglandis is an immigrant callaphidid, monophagous on J. regia. It existed in California for a number of years as an innocuous species, but following the suppression of Chromaphis juglandicola by $T$. pallidus, the dusky veined walnut aphid has, on occasion, become abundant in commercial walnut groves. Chemical control has sometimes been necessary, and Callaphis juglandis now is considered a minor pest (Olson, 1974).

Olson (1974) speculated that the pest status of Callaphis juglandis was due to its release from competitive domination by Chromaphis juglandicola, coupled with its release from the chemical control formerly used against $C$. juglandicola. There is the possibility that Callaphis juglandis has become an economic pest independent of any interrelationship with Chromaphis juglandicola. Instead, its recent economic importance may have resulted from the introduction or development of an ecotype adapted to the hot, arid climate of 

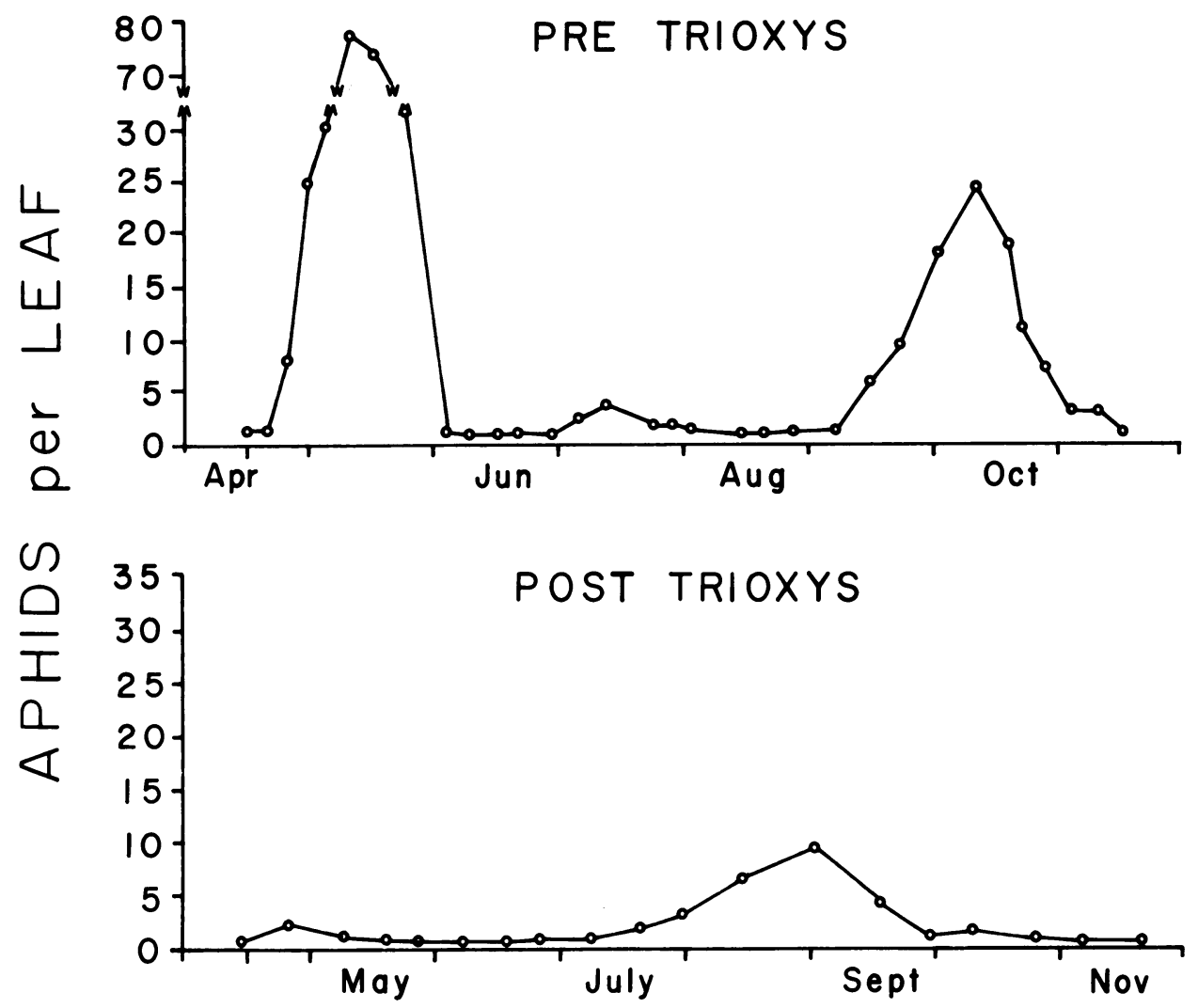

Fig. 4. Hypothetical walnut aphid phenologies in the Reliez Valley before and after the introduction of Trioxys pallidus.

interior California. Whatever the case, Callaphis juglandis now is a minor pest of walnut in California, and a biological control program has been initiated against it.

A second important feature of the successful biological control of the walnut aphid is that it illustrates the critical importance of utilizing proper natural enemy ecotypes in such programs. In this case, use of a suitable $T$. pallidus ecotype turned a virtual failure resulting from the use of a poor ecotype, into an outstanding success.

The effect of $T$. pallidus on the phenology of $C$. juglandicola is another important aspect of the program. Before the introduction of the Iranian T. pallidus, C. juglandicola developed its high- est seasonal population in the springtime, the time of its greatest hazard to the trees and crop. If unchecked by insecticides, the aphids would increase to levels that adversely affected or conditioned the walnut leaves, and then the populations would collapse (Sluss, 1967). These springtime aphid infestations supported predators which at times contributed to the population breakdown. The magnitude of the springtime aphid populations prior to parasite introduction is reflected in the data of Frazer and van den Bosch (1973) who reported a maximum density of about 80 aphids per leaf on Concord variety walnuts in the Reliez Valley in 1969, before $T$. pallidus attained importance. By comparison, population 
maxima of $1.0,1.8,7.9,2.3$, and 1.2 aphids/leaf were recorded during springtime in the years 1970, 1971, 1972 , 1973, and 1974, respectively. A measure of the springtime population potential of the walnut aphid is also reflected in the data from the Tracy insecticide experiment, which show that when $T$. pallidus was inhibited by methoxychlor, the aphid infestation on June 5, 1972, was 46 times greater than that on the untreated trees (Table 1). The data of Sibbett, Barnes, and Davis (1970) and Sibbett, Davis, and Barnes (1971) further reflect the heavy aphid populations that can develop in the absence of $T$. pallidus (Pesticide treatments, page 2.)

There is abundant evidence, then, that $T$. pallidus strongly represses the springtime populations of the walnut aphid. Today when summer comes, virtually all walnut trees in California have been spared heavy aphid infestations and the associated leaf conditioning. This lack of leaf conditioning permits the trees to support high aphid numbers during the summer and autumn until the time of leaf senescence. This was demonstrated in the summertime aphid outbreak in Reliez Valley in 1970, when the Argentine ant interfered with $T$. pallidus (Frazer and van den Bosch, 1973), at Tracy, where the insecticide azinphosmethyl disrupted the aphid-parasite dynamics (Table 1), and at Hanford in 1973 when a protracted period of aphid scarcity led to a collapse of the parasite population, which apparently permitted an aphid eruption.

The phenology of the walnut aphid in California is no longer characterized by a high springtime population peak followed by low level peaks in summer and/or autumn. Instead, at places there is now a low vernal peak followed by a summer peak, usually of greater magnitude, and then another low-level peak in autumn (Fig. 2). In other areas, such as Reliez Valley, there may only be two low-level peaks in spring and autumn (Fig. 1). Hypothetical walnut aphid phenologies in the Reliez Valley, before and after the introduction of T. pallidus, are shown in Figure 4 .

Practices should be avoided that might disrupt the activity of T. pallidus in California walnut orchards, because interference with the parasite could lead to explosive outbreaks of the aphid. Disruption is most likely to result from insecticidal treatments directed toward such pests as codling moth (Laspeyresia pomonella (L.)) or walnut huskfly, but heavy invasions of the Argentine ant also could upset the host-parasite relationship. Available evidence indicates that existing hyperparasites do not have the capacity to severely inhibit the effectiveness of $T$. pallidus.

In summation, although its activities. may occasionally be disrupted in mid or late season by certain largely avoidable factors, and possibly by hyperparasites, T. pallidus has reduced C. juglandicola to minor economic importance.

\section{ACKNOWLEDGMENTS}

Among the many persons who helped in our investigations, we especially acknowledge Ross Sanborn, O. D. McCutcheon, Wallace R. Shreader, Hugh Crawford, Kees G. Eveleens, and Mary
Louise Flint. Funds provided by Diamond Walnut Growers, Inc., and the California Walnut Marketing Board are gratefully acknowledged. 


\section{LITERATURE CITED}

Frazer, B. D., and R. van Den Bosch

1973. Biological control of the walnut aphid in California: the interrelationship of the aphid and its parasite. Environ. Entomol. 2:562-68.

Michelbacher, A. E., and J. C. ORTega

1958. A technical study of insects and related pests attacking walnuts. Calif. Agr. Expt. Sta. Bul. 764:1-87.

Ouson, W. H.

1974. Dusky veined walnut aphid studies. Calif. Agri. 28 (7) :18, 19.

SibbeTT, G. S., M. M. BARNEs, and C. S. DAvis

1970. Dollars and cents reasons for controlling walnut aphid. Diamond Walnut News. April, 1970 , pp. $5,17$.

SibBeTt, G. S., C. S. Davis, and M. M. BARNes

1971. Report from Tulare aphid trials. Diamond Walnut News. April, 1971, pp. 8, 14-15.

SLUSs, R. R.

1967. Population dynamics of the walnut aphid, Chromaphis juglandicola (Kalt.) in northern California. Ecology 48:41-58.

VAN DEN BOSCH, R., E. I. SCHLINGER, and K. S. HAGEN

1962. Initial field observations in California on Trioxys pallidus (Haliday) a recently introduced parasite of the walnut aphid. J. Econ. Entomol. 55:857-62.

vaN Den Bosch, R., B. D. Frazer, C. S. Davis, P. S. Messenger, and R. HoM

1970. An effective walnut aphid parasite from Iran. Calif. Agri. 24:8-10. 
